\title{
An Efficient Approach to the Synthesis of Novel Oxazolidinones as Potential Antimicrobial Agents
}

\author{
Kavita Devi, ${ }^{1}$ Yumna Asmat, ${ }^{2}$ Sonika Jain, ${ }^{2}$ Swapnil Sharma, ${ }^{3}$ and Jaya Dwivedi ${ }^{2}$ \\ ${ }^{1}$ Banasthali University, Banasthali 304022, India \\ ${ }^{2}$ Department of Chemistry, Banasthali University, Banasthali 304022, India \\ ${ }^{3}$ Department of Pharmacy, Banasthali University, Banasthali 304022, India
}

Correspondence should be addressed to Kavita Devi; kavita.singh3632@gmail.com

Received 18 January 2012; Revised 17 June 2012; Accepted 25 June 2012

Academic Editor: Tingyue Gu

Copyright (C) 2013 Kavita Devi et al. This is an open access article distributed under the Creative Commons Attribution License, which permits unrestricted use, distribution, and reproduction in any medium, provided the original work is properly cited.

\begin{abstract}
Oxazolidinone, either mononuclear or condensed with other heterocyclics, has established its importance in medicinal chemistry. A variety of biological activities have been reported by oxazolidinone derivatives. The present work describes the synthesis of several oxazolidinone derivatives, 3-(2-(7-chloroquinoline-4-ylamino)ethyl)-2-imino-5-(4-chloro/nitro/methoxy benzylidene)oxazolidin-4-one 4(a-c) and 4-(2-(7-chloroquinolin-4-ylamino)ethyl)-2(4-chloro/nitro/methoxy-benzylidene)-1,6diox-4,9-di-azaspiro[4,4]nonane-3,8-dione 5(a-c). Synthesized compounds $(1,3,4 \mathrm{a}, 5 \mathrm{a}$, and $5 \mathrm{c})$ were screened against bacterial strains such as S. aureus (MTCC 96) and E. coli (MTCC119) and fungal strains A. niger (MTCC 1344) and C. albicans (MTCC 871) compared with penicillin for bacteria and fluconazole for fungi as reference drugs by disk diffusion method. All synthesized compounds were identified by the means of IR, NMR, and MS.
\end{abstract}

\section{Introduction}

Oxazolidinone derivatives showed very promising activities like monoamine oxidase A [1], cancer [2], HIV [3] and other interesting medicinal properties like aldose reductase inhibitors [4], metabotropic [5], and glutamate receptor antagonists [6]. The chemical literature is showed that chemistry and psychopharmacological properties of these materials have the great importance in medical chemistry, and this has led to an impressive armory of synthetic routes to be developed for these compounds which have resulted in the accumulation of an enormous volume of patented literature in the last decades [7]. In view of this fact, the compounds belonging to this class could be considered as interesting targets in the synthesis of compounds of medicinal interest [8]. On the other hand, it is well known that oxazolidinone derivatives have a great biological relevance; these compounds carry out diverse biological functions, being present in a number of biological systems involving several biochemist reactions of physiological relevance [911]. Although many methods for synthesizing oxazolidinone ring systems have been reported, they continue to receive a great deal of attention. Bacterial and fungal treatment has been a major endeavor of research and development in academic and pharmaceutical industry $[12,13]$. Many of the available antimicrobial agents [14] exhibit undesirable side effects such as reduced bioavailability, toxicity [15], and drug resistance $[16,17]$. Therefore, the search for novel and selective antimicrobial agents is urgently required due to problems associated with currently available antibacterial and fungal drugs.

Hence the significant rising research interest in the design of oxazolidinones as drugs is currently observed in the field of pharmaceutical chemistry. Our present study focused on the synthesis and antimicrobial activities of novel oxazolidinones having quinoline ring.

\section{Experimental}

A chemicals were purchased from Aldrich Chemical Company (USA) and used after purification. The progress of reactions was checked by percolated aluminum silica gel $60 \mathrm{~F}$ 254 thin layer plates. The NMR $\left({ }^{1} \mathrm{H}\right)$ spectra were recorded at 
$300 \mathrm{MHz}$. NMR spectra were obtained in solutions of $\mathrm{CDCL}_{3}$ and chemical shifts reported in parts per million (ppm) and TMS as an internal standard. Melting points were determined by open capillary and uncorrected. IR spectra were recorded on FT-IR Shimadzu 8400 Spectrophotometer and reported in wave numbers $\mathrm{cm}^{-1}$. Column chromatography was performed on silica gel (Merck). Anhydrous sodium sulfate was used as drying agent for the organic phase.

2.1. General Method for the Preparation of $N^{1}$-(7-Chloroquinoline-4-yl)ethane-1,2-diamine (1). A mixture of $2.97 \mathrm{~g}$ (0.59 mol) 4,7-dichloroquinoline and $0.89 \mathrm{~g}$ (0.07 mole) $1-2-$ diaminoethane was dissolved in $30 \mathrm{~mL}$ of distilled ethanol in $250 \mathrm{~mL}$ round bottomed flask and refluxed for $8 \mathrm{~h}$. The progress of the reaction was checked by TLC, and after completion of the reaction, the mixture was cooled and the solvent was evaporated. The solid product obtained was extracted with DCM in presence of brine solution. Organic layer was separated and dried with $\mathrm{Na}_{2} \mathrm{SO}_{4}$. The solvent was evaporated under reduced pressure. The solid obtained was recrystallized from $\mathrm{EtOH}$ (Scheme 1).

2.2. General Method for the Preparation of 2-chloro-N (2(7-Chloroquinoline-4-ylamino)ethyl) Acetamide (2). A mixture of compound $\mathrm{N}$-(7-chloroquinoline-4-yl)ethane-1,2diamine (1) of $2.21 \mathrm{~g}(0.49 \mathrm{mmol})$ and chloroacetyl chloride of $0.75 \mathrm{~mL}(10 \mathrm{mmol})$ dissolved in triethyl amine $(1 \mathrm{~mL})$ and dry EtOH $(25 \mathrm{~mL})$ was stirred for about $30 \mathrm{~min}$ on ice bath then refluxed for 4-6 hr. Progress of the reaction was checked by TLC. After completion the reaction solution was cooled and the solvent was evaporated. The obtained solid product was separated with DCM and water mixture. The organic layer was filtered and dried with $\mathrm{Na}_{2} \mathrm{SO}_{4}$. Resultant product was purified by column chromatography in silica gel $\mathrm{G}$ (methanol and benzene). The eluate was concentrated, and the product was recrystallized from $\mathrm{EtOH}$ to give compound 2 (Scheme 1).

2.3. General Method for the Preparation of 3-(2-(7-Chloroquinoline-4-ylamino)ethyl)-2-iminooxazolid-4-one (3). A mixture of compound (2) 2-chloro-N-(2-(7-chloroquinoline-4-ylamino)ethyl) acetamide of $1.38 \mathrm{~g},(5 \mathrm{mmol})$ and potassium cyanate of $0.58 \mathrm{~g}(7 \mathrm{mmol})$ was dissolved in dry acetone $(10 \mathrm{~mL})$ and refluxed on water bath for about $8 \mathrm{hr}$. The progress of the reaction was checked by TLC using methanol-benzene $(1: 9)$ ratio. After completion of the reaction, the reaction mixture was cooled and solvent was evaporated. The obtained solid product was neutralized by standard solution of $\mathrm{NaHCO}_{3}$ and dried on $\mathrm{Na}_{2} \mathrm{SO}_{4}$ (Scheme 1).

Yields: $63.80 \%$; $\mathrm{Mp}: \quad 80-83^{\circ} \mathrm{C}$; Anal. Calc. for: $\mathrm{C}_{14} \mathrm{H}_{13} \mathrm{ClN}_{4} \mathrm{O}_{2} \mathrm{C}, 55.18 ; \mathrm{H}, 4.39 ; \mathrm{N}, 18.39 ; \mathrm{Cl}, 11.63$; $\mathrm{O}, 10.50$. Found: C, 55.25; H, 4.35; N, 18.45; Cl, 11.65; $\mathrm{O}, 10.65 \% .{ }^{1} \mathrm{H}$ NMR $\left(300 \mathrm{MHz}, \mathrm{CDCl}_{3}\right) \delta 8.84[\mathrm{~s}, 1 \mathrm{H}, \mathrm{NH}]$, 8.65 [s, 1H, ArH], 8.49 [d, 1H, ArH], 8.21 [d, 1H, ArH], 7.86 [d, 1H, ArH], $6.67[\mathrm{~d}, 1 \mathrm{H}, \mathrm{ArH}], 4.14\left[\mathrm{~s}, 2 \mathrm{H}, \mathrm{CH}_{2}\right], 3.80$ [s, 1H, NH], 1.39-1.32 [m, 4H, $\left.\mathrm{CH}_{2}\right] . \mathrm{IR}(\mathrm{KBr}) \mathrm{cm}^{-1} 3057$, 2890 [C-H str.], 1705 [C=O], 1642 [C=NH (Imine)], 1556
[NH (Amine)], 1487 [C-H bend $\mathrm{CH}_{2}$ ], 1345 [C-N str.], 764

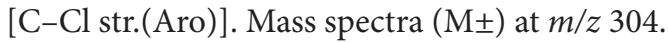

2.4. General Method for the Preparation of 3-[(2-(7Chloroquinolin-4-ylamino)ethyl)-2-imino-5-(4-chlorobenzylidene)] Oxazolidin-4-one (4a). A mixture of compound (3) 3-(2-(7-chloroquinoline-4-ylamino)ethyl)-2-imino-oxazolid-4-one of $0.30 \mathrm{gm}(0.12 \mathrm{mmol})$, sodium acetate $0.10 \mathrm{gm}$, and p-chlorobenzaldehyde of $0.127 \mathrm{gm}(0.171 \mathrm{mmol})$ was dissolved in dry benzene $(20 \mathrm{~mL})$. The reaction mixture was refluxed on water bath for $8 \mathrm{hr}$ at $80-100^{\circ} \mathrm{C}$. The progress of the reaction was checked by TLC using methanolbenzene $(1: 9)$ ratio as an eluent. After completion of the reaction, the reaction mixture was cooled and solvent was evaporated. The obtained product was purified by column chromatography and recrystallized with ethanol to give 3-[(2-(7-chloroquinolin-4-ylamino)ethyl)-2-imino-5-(4chlorobenzylidene)] oxazolidin-4-one (Scheme 1).

2.5. General Method for the Preparation of 3-[(2-(7-Chloroquinolin-4-ylamino)ethyl)-2-imino-5-(4-nitrobenzylidene)] Oxazolidin-4-one (4b). A mixture of compound (3) 3-(2-(7chloroquinoline-4-ylamino)ethyl)-2-imino-oxazolid-4-one of $0.30 \mathrm{gm}(0.13 \mathrm{mmol})$, sodium acetate of $0.10 \mathrm{gm}$, and p-nitrobenzaldehyde of $0.37 \mathrm{gm}(0.038 \mathrm{mmol})$ was dissolved in dry benzene $(20 \mathrm{~mL})$. The reaction mixture was refluxed on water bath for $8 \mathrm{hr}$ at $80-100^{\circ} \mathrm{C}$. The progress of the reaction was checked by TLC using methanol-benzene (1:9) ratio as an eluent. After completion of the reaction, the reaction mixture was cooled and the solvent was evaporated. The obtained product was purified by column chromatography and recrystallized with ethanol to give 3[(2-(7-chloroquinolin-4-ylamino) ethyl-2-imino-5-(4-nitro benzylidene)] oxazolidin-4-one (Scheme 1).

2.6. General Method for the Preparation of 3-[(2-(7Chloroquinolin-4-ylamino)ethyl)-2-imino-5-(4-methoxybenzylidene)] Oxazolidin-4-one (4c). A mixture of compound (3) 3-(2-(7-chloroquinoline-4-ylamino)ethyl)-2-iminooxazolid-4-one $0.30 \mathrm{gm} \quad(0.12 \mathrm{mmol})$, zinc chloride of $0.50 \mathrm{mg}$, and p-methoxybenzaldehyde of $0.127 \mathrm{gm}$ $(0.017 \mathrm{mmol})$ was dissolved in glacial acetic acid $(20 \mathrm{~mL})$. The reaction mixture was refluxed on sand bath for $8 \mathrm{hr}$ at $120^{\circ} \mathrm{C}$. The progress of the reaction was checked by TLC using methanol-benzene $(1: 9)$ ratio as an eluent. After completion of the reaction, solution was cooled and neutralized with $\mathrm{NaHCO}_{3}$, to obtained white precipitated compound. The compound crystallized with methanol and water and recrystallized with ethanol to give 3-[(2-(7-chloroquinolin4-ylamino)ethyl)-2-imino-5-(4-methoxybenzylidene)] oxazolidin-4-one (Scheme 1).

Yields: 67\%; Mp: 85-87 C; Anal. Calc. for: $\mathrm{C}_{24} \mathrm{H}_{19} \mathrm{ClN}_{4} \mathrm{O}_{3}$ C, 62.49; H, 4.53; N, 13.25; Cl, 8.38; O, 11.53. Found: C, 62.43; $\mathrm{H}, 4.51$; N, 13.20; Cl, 8.40; O, 11.25\%. ${ }^{1} \mathrm{H}$ NMR $(300 \mathrm{MHz}$, $\left.\mathrm{CDCl}_{3}\right) \delta 9.84[\mathrm{~s}, 1 \mathrm{H},(\mathrm{NH})], 8.90[\mathrm{~s}, 1 \mathrm{H}, \mathrm{Ar} . \mathrm{H}], 8.70[\mathrm{~d}$, $1 \mathrm{H}, \mathrm{ArH}$ ], 8.69 [d, 1H, ArH] 8.12 [d, 1H, ArH], 8.90 [s, 1H, $\mathrm{ArH}], 8.01$ [d, 1H, ArH] 7.80 [d, 1H, ArH], 7.41[d, 1H, ArH], $7.39[\mathrm{~s}, 2 \mathrm{H}, \mathrm{C}=\mathrm{CH}], 6.97[\mathrm{~d}, 1 \mathrm{H}, \mathrm{ArH}], 6.71[\mathrm{~d}, 1 \mathrm{H}, \mathrm{ArH}]$, 

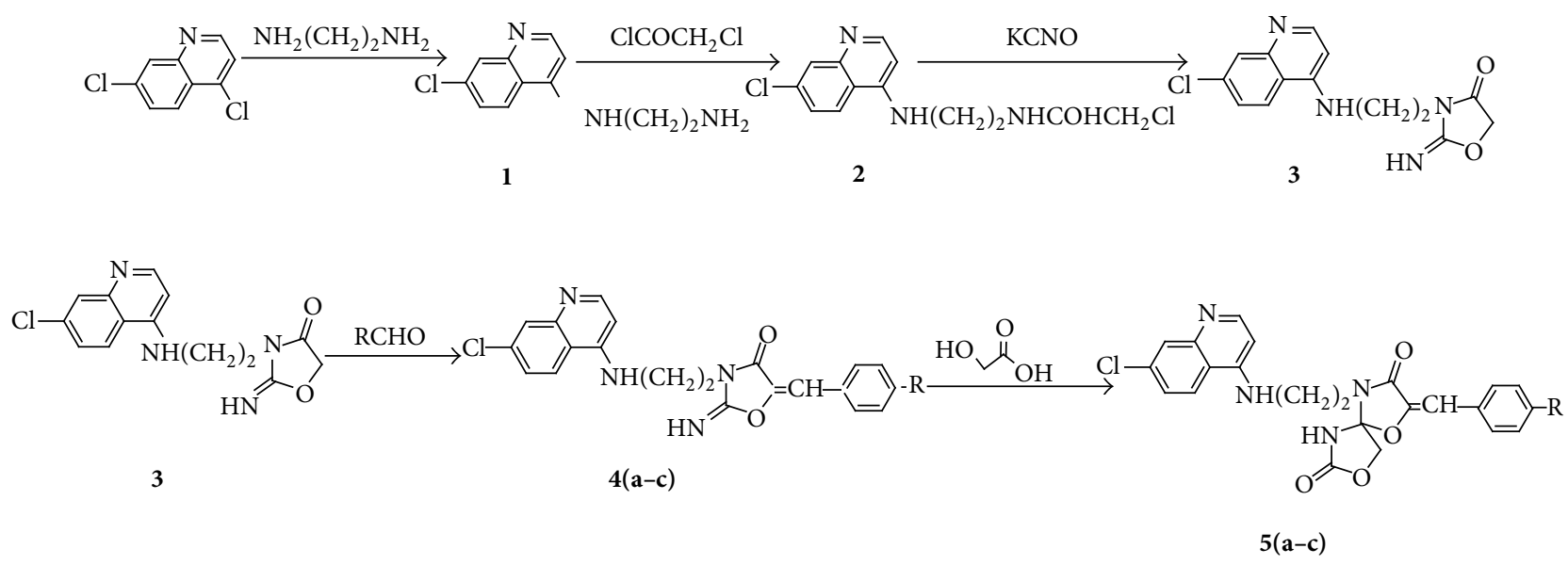

Where $\mathrm{R}=\mathrm{Cl}, \mathrm{NO}_{2}, \mathrm{OCH}_{3}$

SCHEMe 1

$3.83\left[\mathrm{~s}, 3 \mathrm{H}\left(\mathrm{CH}_{3}\right)\right], 4.24[\mathrm{~s}, 1 \mathrm{H},(\mathrm{NH})], 1.5-1.2\left[\mathrm{~m}, 4 \mathrm{H}\left(\mathrm{CH}_{2}\right)\right]$. IR $(\mathrm{KBr}) \mathrm{cm}^{-1}$ 3140, 3021 [CHstr.Ar.H], 1704 [C=O], 1652 [C=C str.], 1591[NH str.(Imine)], 1551 [NH str.(Amine)], 1462 [C-H bend. $\mathrm{CH}_{2}$ ], 1300 [C-O(Ester)], 1249[C-N str.], 751 [C-Cl str.]. Mass spectra $(\mathrm{M} \pm)$ at $m / z 422$.

2.7. General Method for the Preparation of 4-(2-(7-Chloroquinolin-4-ylamino)ethyl)-2-(4-chlorobenzylidene)-1,6dioxa-4,9-diazaspiro[4,4]nonane-3,8-dione (5a). A compound (4a) 3-(2-(7-chloroquinolin-4-ylamino)ethyl)-2-imino-5-(4-chlorobenzylidene) oxazolidin-4-one of $0.30 \mathrm{gm}$ $(0.12 \mathrm{mmol})$ and glycolic acid of $3.37 \mathrm{gm}(0.25 \mathrm{mmol})$ was dissolved in dry benzene $(20 \mathrm{~mL})$ and refluxed on water bath for about $24 \mathrm{hr}$. The progress of the reaction was checked by TLC using methanol-benzene $(2: 8)$ as an eluent. After completion of the reaction, it was cooled and neutralized with aqueous standard solution of sodium bicarbonate $\left(\mathrm{NaHCO}_{3}\right)$ and water successively and purified by column chromatography to obtain 4-(2-(7-chloroquinolin-4-ylamino)ethyl)-2(4-chlorobenzylidene)-1,6-diox-4,9-diazaspiro[4,4]nonane-3,8-dione (Scheme 1).

Yields: 58\%; Mp: $121-124^{\circ} \mathrm{C}$; Anal. Calc. for: $\mathrm{C}_{23} \mathrm{H}_{18} \mathrm{ClN}_{4} \mathrm{O}_{4} \mathrm{C}, 56.92 ; \mathrm{H}, 3.74 ; \mathrm{N}, 11.54 ; \mathrm{Cl}, 14.38 ;$ $\mathrm{O}, 13.19$. Found: C, 56.80; H, 3.70; N, 11.40; Cl, 14.40; O, $13.21 \% .{ }^{1} \mathrm{H}$ NMR $\left(300 \mathrm{MHz}, \mathrm{CDCl}_{3}\right) \delta 8.86[\mathrm{~s}, 1 \mathrm{H},(\mathrm{NH})]$, 8.18 [d, 1H, ArH] 8.15 [d, 1H, ArH] 8.03 [d, 1H, ArH] 8.01 [s, 1H, ArH], 7.84 [d, 1H, ArH] , 7.77-737 [dd, 2H, ArH], 7.27 [dd, $2 \mathrm{H}, \mathrm{ArH}], 3.65\left[\mathrm{~s}, 2 \mathrm{H},\left(\mathrm{CH}_{2}\right)\right], 1.59-1.22\left[\mathrm{~m}, 4 \mathrm{H}\left(\mathrm{CH}_{2}\right)\right]$. $\operatorname{IR}(\mathrm{KBr}) \mathrm{cm}^{-1} 6.83[\mathrm{~s}, 2 \mathrm{H},(\mathrm{C}=\mathrm{CH})], 4.00[\mathrm{~s}, 1 \mathrm{H}, \mathrm{NH}], 3269$ [NHstr.(Amine)], 3031, 2962 [CH(str.)], $1715[\mathrm{C}=\mathrm{O}$ (str.)], $1652[\mathrm{C}=\mathrm{CH}], 1510\left[\mathrm{NH}\right.$ (Amine)], 1452 [C-H(bend) $\left.\mathrm{CH}_{2}\right]$, 1336 [C-N(str.)], 762,675 [C-Cl str.(Aro)]. Mass spectra $(\mathrm{M} \pm)$ at $m / z 485$.

2.8. General Method for the Preparation of 4-(2-(7-Chloroquinolin-4-ylamino)ethyl)-2-(4-nitrobenzylidene)-1,6-dioxa4,9-diazaspiro[4,4]nonane-3,8-dione (5b). A compound (4b) 3-(2-(7-chloroquinolin-4-ylamino)ethyl)-2-imino-5-(4nitrobenzylidene) oxazolidin-4-one of $0.30 \mathrm{gm}(0.12 \mathrm{mmol})$ and glycolic acid of $3.37 \mathrm{gm}(0.25 \mathrm{mmol})$ was dissolved in dry benzene $(20 \mathrm{~mL})$ and refluxed on water bath for about $24 \mathrm{hr}$. The progress of the reaction was checked by TLC using methanol-benzene $(2: 8)$ as an eluent. After completion of the reaction, it was cooled and neutralized with aqueous standard solution of sodium bicarbonate $\left(\mathrm{NaHCO}_{3}\right)$ and water successively and purified by column chromatography to obtain 4-(2-(7-chloroquinolin-4-ylamino)ethyl)-2(4-nitro benzylidene)-1,6-diox-4,9-diazaspiro[4,4]nonane-3,8-dione (Scheme 1).

2.9. General Method for the Preparation of 4-(2-(7-Chloroquinolin-4-ylamino)ethyl)-2-(4-methoxybenzylidene)-1,6-dioxa-4,9-diazaspiro[4,4] nonane-3,8-dione (5c). A compound (4c) 3-(2-(7-chloroquinolin-4-ylamino)ethyl-2-imino-5-(4methoxybenzylidene) oxazolidin-4-one of $0.30 \mathrm{gm}(0.12$ $\mathrm{mmol}$ ), zinc chloride of $0.50 \mathrm{mg}$, and glycolic acid $3.37 \mathrm{gm}$ $(0.25 \mathrm{mmol})$ was dissolved in glacial acetic acid $(20 \mathrm{~mL})$ and refluxed on sand bath for about 6-7 hr. The temperature of the reaction mixture was raised to $120^{\circ} \mathrm{C}$ and maintained at the same temperature. The progress of the reaction was checked by TLC using methanol-benzene $(2: 8)$ as an eluent. After completion of the reaction, it was cooled and neutralized with ammonium hydroxide and purified by column chromatography to obtain 4 -(2-(7-chloroquinolin4-ylamino)ethyl)-2(4-methoxy-benzylidene)-1,6-diox-4,9diazaspiro[4,4]nonane-3,8-dione (Scheme 1).

Yields: 57\%; Mp: $130-134^{\circ} \mathrm{C}$; Anal. Calc. for: $\mathrm{C}_{24} \mathrm{H}_{21} \mathrm{ClN}_{4} \mathrm{O}_{5}, \mathrm{C}, 59.94 ; \mathrm{H}, 4.40 ; \mathrm{N}, 11.65 ; \mathrm{Cl}, 7.37 ; \mathrm{O}$, 16.65. Found: C, 59.97; H, 4.23; N, 11.60; Cl, 7.40; O, 16.75\%. ${ }^{1} \mathrm{H}$ NMR $\left(300 \mathrm{MHz}, \mathrm{CDCl}_{3}\right) \delta 8.62[\mathrm{~s}, 1 \mathrm{H}, \mathrm{NH}], 8.01$ [s, 1H, Ar.H], 7.65 [d, 1H, ArH], 7.48 [d, 1H, ArH], 7.15 [dd, $2 \mathrm{H}, \mathrm{ArH}$ ] $, 7.04[\mathrm{~d}, 1 \mathrm{H}, \mathrm{ArH}], 6.83$ [s, 2H, $\left.\left(\mathrm{Ar} . \mathrm{CH}_{2}\right)\right], 6.72[\mathrm{dd}$, $2 \mathrm{H}, \mathrm{ArH}], 6.41[\mathrm{~d}, 1 \mathrm{H}, \mathrm{ArH}], 4.87$ [s, 2H, $(\mathrm{C}=\mathrm{CH})], 4.26$ [s, $1 \mathrm{H}, \mathrm{NH}], 3.25\left[\mathrm{~s}, 3 \mathrm{H},\left(\mathrm{CH}_{3}\right)\right], 1.31-1.44\left[\mathrm{~m}, 4 \mathrm{H}\left(\mathrm{CH}_{2}\right)\right] . \mathrm{IR}$ 
TABLE 1: In vitro antibacterial activities of compounds $\mathbf{1 , 3}, \mathbf{4 a}, \mathbf{4 c}$ and $\mathbf{5 c}$ against different strains.

\begin{tabular}{lcccccc}
\hline \multirow{2}{*}{ Strains } & & \multicolumn{4}{c}{ \% of activity } \\
& Compound $\mathbf{1}$ & Compound 3 & Compound 4a & Compound 5a & Compound 5c & Penicillin \\
\hline Staphylococcus aureus & 85.28 & 86.65 & 84.24 & 86.68 & 88.26 \\
Escherichia coli & 78.51 & 82.76 & 75.99 & 90.75 & 85.23 \\
\hline
\end{tabular}

TABLE 2: In vitro antifungal activities of compounds $\mathbf{1 , 3 , 4 a}, \mathbf{4 c}$ and $\mathbf{5 c}$ against different strains.

\begin{tabular}{lcccccc}
\hline \multirow{2}{*}{ Strains } & & \multicolumn{4}{c}{ \% of activity } \\
& Compound $\mathbf{1}$ & Compound 3 & Compound 4a & Compound 5a & Compound 5c & Fluconazol \\
\hline Candida albicans & 76.87 & 76.98 & 73.90 & 82.82 & 83.53 & 70.00 \\
Aspergillus niger & 75.45 & 70.31 & 74.89 & 72.65 & 78.34 & 70.00 \\
\hline
\end{tabular}

(KBr) $\mathrm{cm}^{-1} 1445$ [C-H (bend) $\mathrm{CH}_{2}$ ], 3295[NH str.(Amine)], 3062, 2945 [C-H str.], 1719 [C=O(str.)], 1657 [C=CH], 1516 [NH (Amine)], 1321[C-N str.], 1298 [C-O(str.)], 785 [C-Cl str.(Aro)]. Mass spectra $(\mathrm{M} \pm)$ at $m / z 480$.

\section{Results and Discussion}

The key intermediate 1 was prepared by nucleophilic reaction involving 4,7-dichloroquinoline and 1,2-diaminoethane in the presence of ethanol. $\mathrm{N}^{1}$-(7-Chloroquinoline-4-yl)ethane1,2-diamine (1) reacted with chloroacetyl chloride and give 2-chloro-N (2-7-Chloroquinoline-4-ylamino)ethyl) Acetamide (2). Imino-oxazolidi-4-one derivatives (3) was obtained from acetamide (chloroacetanilide) derivatives, by nucleophilic attack of cyanate functional group of potassium cyanate followed by cyclization in dry acetone medium. Imino-5-(4-substituted benzylidene) oxazolidin4-one derivatives $(4 a-c)$ were obtained by the refluxing of substituted aldehydes paracholoro, paranitro, and paramethoxy benzaldehydes with imino oxazolidinone derivatives $(3)$ to generate $4(\mathrm{a}-\mathrm{c})$. Spiro-oxazolidinone derivatives $5(\mathrm{a}-\mathrm{c})$ were obtained by the reaction of imino5-(4-substituted benzylidene) oxazolidin-4-one derivatives $4(\mathrm{a}-\mathrm{c})$ with glycolic acid in dry benzene medium. The synthetic route of the compounds is outlined in Scheme 1. The newly synthesized compounds were characterized by FT-IR, NMR (1H) and mass spectral data.

\section{Antimicrobial Activity}

Five of the newly synthesized compounds were evaluated for their in vitro antibacterial activity against $S$. aureus (MTCC 96) and E. coli (MTCC119) and antifungal activity against $A$. niger (MTCC 1344) and C. albicans (MTCC 871) organisms. Disk diffusion method was used for the determination of the preliminary antibacterial and antifungal activities. Penicillin for bacteria and fluconazole for fungi were used as reference drugs. The results depicted in Tables 1 and 2 revealed that most of the tested compounds displayed variable inhibitory effects on the growth of the tested organisms. Regarding the activity of the oxazolidinone derivatives against bacteria, the results revealed that compounds $\mathbf{5} \mathbf{c}$ and $\mathbf{4 a}$ exhibited broad spectrum of antibacterial profiles against the tested organisms. Regarding the activity of oxazolidinones derivative against antifungal strains the results revealed that compounds $5 \mathbf{a}$ and $\mathbf{5} \mathbf{c}$ revealed strong growth inhibition against the tested fungi.

\section{Conclusion}

In conclusion, the objective of the present study was to synthesize and investigate the antimicrobial activities of some new heterocyclic oxazolidinone derivatives. Our aim was to synthesize the compounds by the incorporating oxazolidinones and quinoline nucleus with substituted benzaldehyde into one molecular framework which is view to examine change if any. if such an association could produce a favorable impact on the biological properties in the newer synthetic materials. The obtained results clearly revealed that some of the newly synthesized compounds exhibited better anti microbial activity

\section{Acknowledgments}

The authors are grateful to the Director, CDRI Lucknow, and Dr. Anees A. siddiqui, Jamiya Hamdard University Delhi, for providing the ${ }^{1} \mathrm{H}-\mathrm{NMR}$ data of the compounds and Department of Biotechnology, Banasthali University for providing antimicrobial data. They are also thankful to the departments of Bioscience and Biotechnology for antimicrobial activity. They are greatly thankful for financial support provided by Department of Science and Technology (DST), New Delhi for the project "Banasthali Center for Education and Research in Basic Sciences" under their CURIE (Consolidation of University Research for Innovation and Excellence in Women Universities) programme.

\section{References}

[1] T. Z. E. Jones, P. Fleming, C. J. Eyermann, M. B. Gravestock, and R. R. Ramsay, "Orientation of oxazolidinones in the active site of monoamine oxidase," Biochemical Pharmacology, vol. 70, no. 3, pp. 407-416, 2005. 
[2] M. Rami, R. Macherla et al., Patent number 7879892, 2008.

[3] M. G. Madariaga and S. Swindells, "Oxazolidinones and human immunodeficiency virus," Antimicrobial Agents and Chemotherapy, vol. 51, no. 3, p. 1130, 2007.

[4] S. Rapposelli, F. Da Settimo, M. Digiacomo et al., "Synthesis and biological evaluation of $2^{\prime}$-oxo-2,3-dihydro- $3^{\prime} \mathrm{H}$ spiro[chromene- $4,5^{\prime}$-[1,3] oxazolidin]-3' yl] acetic acid derivatives as aldose reductase inhibitors," Archiv der Pharmazie, vol. 344, no. 6, pp. 372-385, 2011.

[5] E. J. Brnardic, M. E. Fraley, and R. M. Garbaccio Bioorg, "3Aryl-5-phenoxymethyl-1,3-oxazolidin-2-ones as positive allosteric modulators of mGluR2 for the treatment of schizophrenia: hit-to-lead efforts ," Bioorganic \& Medicinal Chemistry Letters, vol. 20, no. 10, pp. 3129-3133, 2010.

[6] S. Welsch-Kunze and K. Kuschinsky, "On the possible involvement of glutamate receptors in conditioning of behavioural effects of apomorphine," Psychopharmacology, vol. 101, no. 3, pp. 421-428, 1990.

[7] G. Zappia, P. Menendez, G. Delle Monache, D. Misiti, L. Nevola, and B. Botta, "The contribution of oxazolidinone frame to the biological activity of pharmaceutical drugs and natural products," Mini-Reviews in Medicinal Chemistry, vol. 7, no. 4, pp. 389-409, 2007.

[8] K. Devi, Y. Asmat, P. Sahi, S. Sharma, and J. Dwivedi, "Announcement," International Journal of Pharmaceutical Sciences and Research, vol. 2, pp. 124-129, 2012.

[9] H. Kakeya, M. Morishita, K. Kobinata, M. Osono, M. Ishizuka, and $\mathrm{H}$. Osada, "Isolation and biological activity of a novel cytokine modulator, cytoxazone," Journal of Antibiotics, vol. 51, no. 12, pp. 1126-1128, 1998.

[10] C. J. Fowler and S. B. Ross, "Selective inhibitors of monoamine oxidase A and B: biochemical, pharmacological, and clinical properties," Medicinal Research Reviews, vol. 4, no. 3, pp. 323-358, 1984.

[11] E. V. Bobkova, Y. Ping Yan, D. B. Jordan, M. G. Kurilla, and D. L. Pompliano, "Catalytic properties of mutant $23 \mathrm{~S}$ ribosomes resistant to oxazolidinones," The Journal of Biological Chemistry, vol. 278, no. 11, pp. 9802-9807, 2003.

[12] P. L. Dostert, M. S. Benedetti, and K. F. Tipton, "Interactions of monoamine oxidase with substrates and inhibitors," Medicinal Research Reviews, vol. 9, no. 1, pp. 45-89, 1989.

[13] T. P. Shiau, E. D. Turtle, C. Francavilla et al., "Novel 3chlorooxazolidin-2-ones as antimicrobial agents," Bioorganic and Medicinal Chemistry Letters, vol. 21, no. 10, pp. 3025-3028, 2011.

[14] A. M. Slee, M. A. Wuonola, R. J. McRipley et al., "Oxazolidinones, a new class of synthetic antibacterial agents: in vitro and in vivo activities of DuP 105 and DuP 721," Antimicrobial Agents and Chemotherapy, vol. 31, no. 11, pp. 1791-1797, 1987.

[15] A. R. Renslo, "Antibacterial oxazolidinones: emerging structure-toxicity relationships," Expert Review of Anti-infective Therapy, vol. 8, no. 5, pp. 565-574, 2010.

[16] C. A. Quesnelle, P. Gill, S. Roy et al., "Biaryl isoxazolinone antibacterial agents," Bioorganic and Medicinal Chemistry Letters, vol. 15, no. 11, pp. 2728-2733, 2005.

[17] R. K. Mishra, K. D. Revell, C. M. Coates, E. Turos, S. Dickey, and D. V. Lim, "In vitro photo-release of a TRPV1 agonist," Bioorganic \& Medicinal Chemistry Letters, vol. 16, no. 1, pp. 208-212, 2006. 

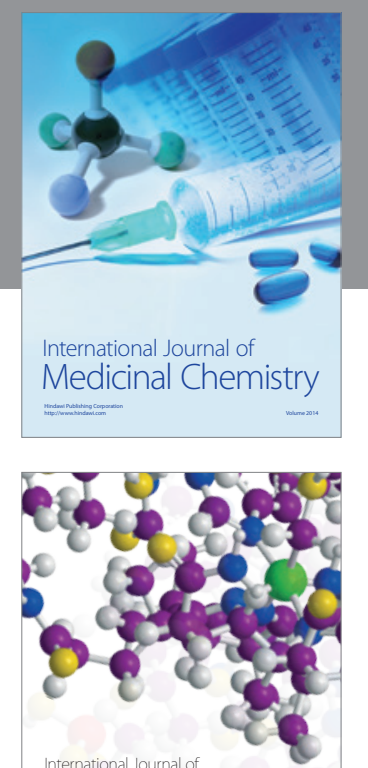

\section{Carbohydrate} Chemistry

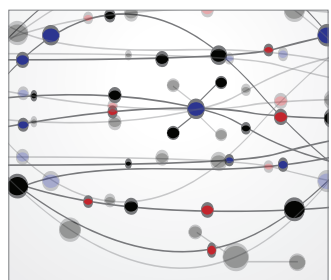

The Scientific World Journal
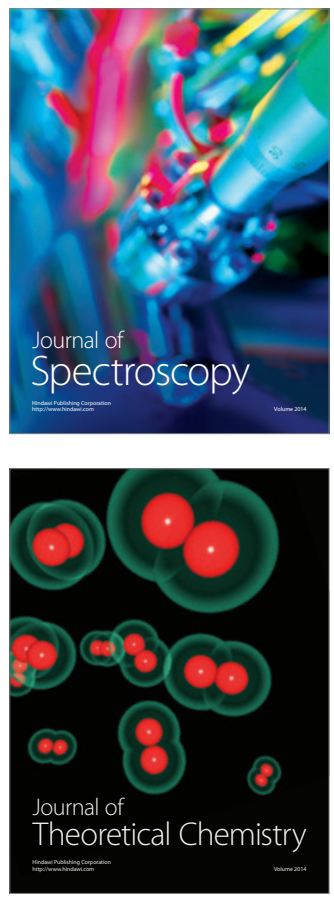
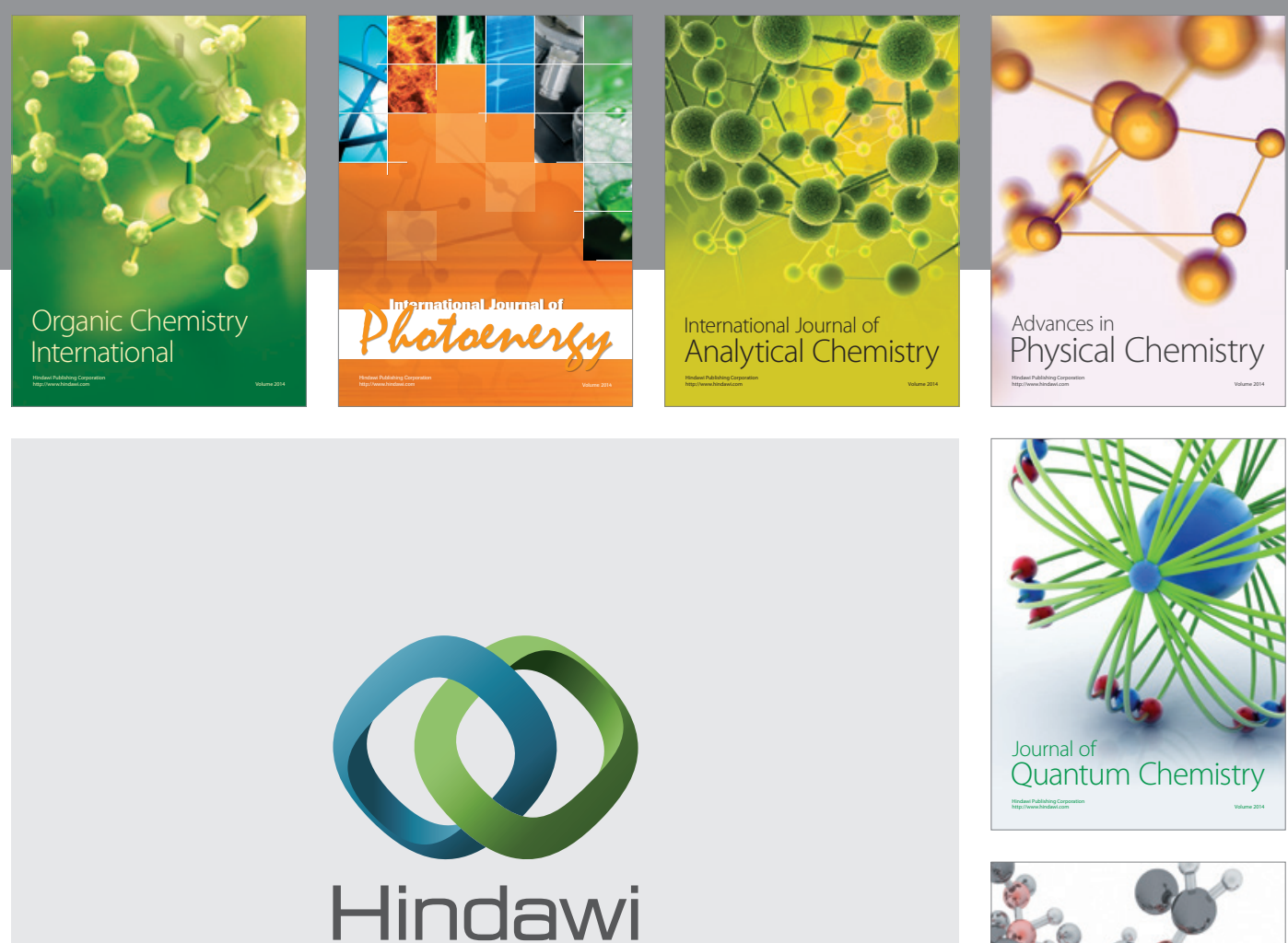

Submit your manuscripts at

http://www.hindawi.com

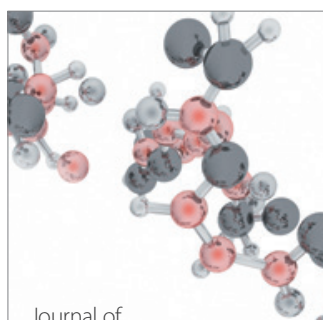

Analytical Methods

in Chemistry

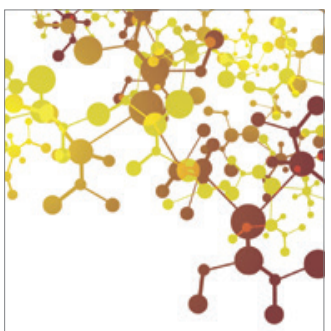

Journal of

Applied Chemistry

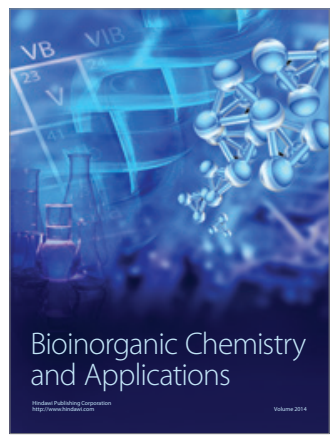

Inorganic Chemistry
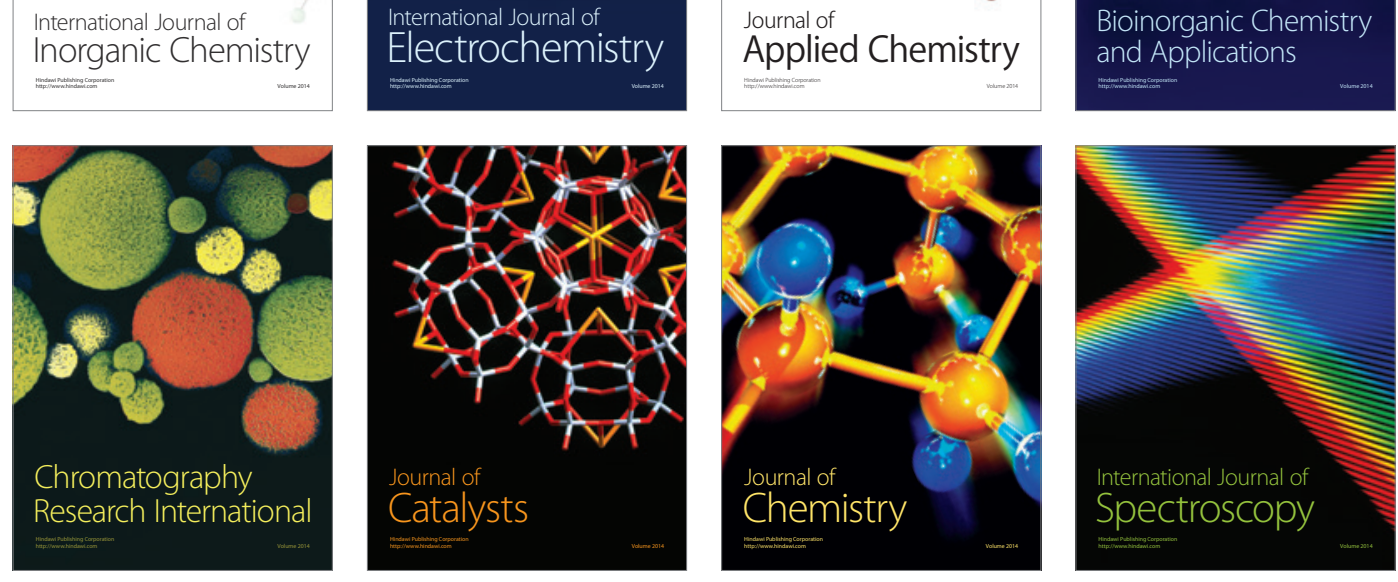